Appl. Math. Mech. -Engl. Ed., 32(11), 1489 (2011)

DOI 10.1007/s10483-011-1517-x

(C)Shanghai University and Springer-Verlag

\title{
Retraction note
}

Berlin Heidelberg 2011

\section{Retraction note: Similarity solutions for creeping flow and heat transfer in second grade fluid}

Retraction: Muhammet Yürüsoy. Similarity solutions for creeping flow and heat transfer in second grade fluid. Applied Mathematics and Mechanics (English Edition), 25(4), 467-474 (2004) DOI: 10.1007/BF02437531

This article is retracted because of duplicate publication.

Applied Mathematics and Mechanics (English Edition) Sept. 28, 2011 